\title{
Scintigraphy with J001X, a Klebsiella membrane glycolipid, for the early diagnosis of chronic berylliosis: results from an experimental model
}

\author{
P Diot, A Le Pape, D Nolibe, G Normier, H Binz, J P Revillard, G Lasfargues, M Lavandier, \\ E Lemarié
}

\begin{abstract}
A glycolipid (J001X) isolated from the membrane proteoglycans of a non-pathogenic strain of Klebsiella pneumoniae was developed to bind selectively to macrophages. A scintigraphic technique could thus be developed and applied to an experimental model of lung berylliosis. Six baboons were injected intratracheally with a beryllium metal suspension. Three to 24 months later, they were submitted to both an anatomical and a functional respiratory evaluation. Two baboons were explored at the early stage of alveolitis and four baboons at a more advanced stage characterised by a granulomatous disorder. Scintigraphy was performed using J001X labelled with ${ }^{99 m}$ technetium administered as an aerosol. In the six baboons, conventional imaging techniques (chest $x$ ray film, computed tomography scan, gallium scintigraphy), failed to show either any lung abnormality or mediastinal lymph nodes consistent with beryllium disease. In the two recently contaminated baboons, J001X scintigraphy showed a well defined parenchymal fixation facing the contaminated lobe. In the four baboons who were at a more advanced stage of berylliosis, J001X fixation was always focused paratracheally without any significant involvement of the lung parenchyma. The subcarinal and laterotracheal lymph nodes seen at necropsy corresponded to J001X scintigraphic fixations. In
\end{abstract}

Laboratoire de Biophysique Cellulaire, INSERMU316, Faculté de Médecine, Tours, France

P Diot, A Le Pape, G Lasfargues, $M$ Lavandier, E Lemarié INSTN-CEA, Saclay, France

A Nolibe

Centre d'Immunologie et de Biotechnologie Pierre Fabre, Saint Julien en Genevois, France

G Normier, H Binz

Laboratoire d'Immunologie, INSERM-U80, Hôpital

E Herriot, Lyon, France

J P Revillard conclusion, when compared with conventional techniques such as chest $\boldsymbol{x}$ ray film, computed tomography scan, magnetic resonance imaging, and gallium scintigraphy, J001X scintigraphy has proved its ability to detect occult lesions in experimental berylliosis in baboons. By comparison with gallium scintigraphy, scintigraphy with J001X appears to have superior sensitivity and can be performed in four hours.

Beryllium is a light metal with physicochemical characteristics (high melting point, low density, high modulus of elasticity, low coefficient of thermal expansion) that has led to an extensive use in modern industries such as the space programme and nuclear power (electrical energy, military, and medical applications). ${ }^{12}$ Through a direct irritant effect of the metal, acute exposure to beryllium may lead to an inflammation of the mucous membranes and the respiratory tract. Chronic berylliosis is a systemic granulomatous disease that primarily affects the lungs. As defined by a beryllium case registry established at the Masachusetts General Hospital, the criteria for diagnosis requires evidence of an exposure to beryllium and a clinical, radiological, and functional course of an interstitial lung disease. ${ }^{3}$ The current hygienic standards prescribed for the professional use of beryllium are strict but probably do not suppress any risk for exposed workers. So, a problem at the present time is to detect occult berylliosis before clinical, radiological, and functional evidence. To this end, in vitro tests for the exploration of immune function have been developed. ${ }^{4}$ Another strategy could be the scintigraphic imaging of the granulomatous foci using agents able to target selectively the lesion associated macrophages. ${ }^{5} \mathrm{~J} 001 \mathrm{X}$ is a $34 \mathrm{kD}$ chemically characterised Klebsiella membrane glycolipid that selectively concentrates into macrophages. ${ }^{6}$ Due to amphiphatic properties, J001X molecules are fully and rapidly trapped by liver and spleen when intravenously injected. A systemic transfer of the molecules through the res- 
piratory tract is possible, however, after administration by aerosol. In these conditions, J001X labelled with ${ }^{99 \mathrm{~m}}$ technetium and administered as an aerosol, has proved to be efficient for the imaging of lymph nodes and lung granuloma in human sarcoidosis. ${ }^{6}$ In the present study J001X scintigraphy was performed in an experimental model of lung berylliosis in baboons to assess if this technique could be of value for detecting occult berylliosis.

\section{Materials and methods}

\section{ANIMALS}

Six Papio papio baboons (two males and four females) identified as numbers $336,342,433,444$, 465 , and 482 , and weighing 6 to $8 \mathrm{~kg}$ were housed according to EC guidelines and explored using noninvasive imaging techniques in agreement with good laboratory practices. Before the exposure to beryllium they were submitted to an anatomical and functional respiratory evaluation as further described.

\section{EXPOSURE TO BERYLLIUM}

Baboons were anaesthetised by intramuscular injection of $10 \mathrm{mg} / \mathrm{kg}$ ketamine (Imalgene 500 , Iffa Merieux, France) and were injected intratracheally with a beryllium metal suspension through a tracheal tube placed just above the carina. Due to the anatomical configuration of the bronchi, the right lower lobe was the most contaminated part of the lung. The suspension was prepared from powdery beryllium metal. A relatively homogeneous preparation was obtained after differential sedimentation: the median aerodynamic diameter of particles was $3.6 \mu \mathrm{m}$. The total dose of beryllium administered to baboons ranged from $30-100 \mathrm{mg}$. This was achieved with either two or five administrations of $15-20 \mathrm{mg}$ each given with a three day delay between successive instillations.

\section{RADIOLOGICAL INVESTIGATIONS}

Chest $x$ ray film and computed tomography scan (Tomoscan A310, Philips) were performed both before and three to 24 months after beryllium contamination on ketamine anaesthetised animals. Baboons 433, 465, and 482 whose J001X fixations were very close together were submitted to $1.5 \mathrm{~T}$ magnetic resonance imaging on a Magnetom system (Siemens) at the Nantes University Hospital Centre (France).

\section{J001X SCINTIGRAPHY}

One mg freeze dried J001X (Laboratoires Pierre Fabre, France) was dissolved in $1 \mathrm{ml}$ isotonic saline and labelled under vacuum with $740 \mathrm{MBq}$ sodium ${ }^{99 \mathrm{~m}}$ pertechnetate, in the presence of $200 \mu \mathrm{g}$ stannous chloride Radiolabelled J001X was administered as an aerosol using an ultrasound TV 6000 inhaler (Siemens, Germany) operating at $110 \mathrm{kHz}$. Exposure to aerosol was always limited to 15 minutes to prevent any oxidation that could degrade the radiolabelling of the preparation.

During the first hour after exposure to aerosol, a series of 12 dynamic images was recorded each five minutes long. The scintigraphy was completed by three static images recorded respectively two, three, and four hours after the inhalation. The radioactive $\mathrm{J} 001 \mathrm{X}$ concentrations in fixing areas were determined by referring their counts to those of contralateral healthy areas.

\section{COMPLEMENTARY SCINTIGRAPHIC INVESTIGATIONS}

The animals were systematically submitted every month to the following tests:

${ }^{99 m}$ Technetium-DTPA aerosol with a TCK6 kit from CIS bio international (France).

${ }^{67}$ Gallium citrate scintigraphy with $9 \cdot 25 \mathrm{MBq}$ (CIS bio international), images being recorded 24, 48 , and 72 hours after intravenous injection of the tracer.

The ${ }^{99 \mathrm{~m}}$ technetium-DTPA aerosol administration was performed to evaluate both the ventilation and the alveolocapillary permeability. Gallium scintigraphy was chosen as the scintigraphic reference agent for the assessment of granulomatous disorders of the lung. All scintigraphies were performed on the posterior surface of the chest, on conscious baboons maintained in a specially designed chair. A Pho Gamma camera Searle equipped with a high resolution parallel $140 \mathrm{keV}$ collimator was used. It was connected to a TIM 512 MEDIMAG (Besançon, France) computer for data processing on images recorded using a $128 \times 128$ matrix.

Further examinations were required in some cases to precisely identify the anatomical structures seen in the fixation of J001X. Angiocardiography was done when necessary by intravenous injection of $185 \mathrm{MBq}$ $\mathrm{TCO}_{4}^{-}$at the end of the J001X scintigraphy. For the same purpose, oesophageal scintigraphy was also performed during ingestion of $37 \mathrm{MBq} \mathrm{TCO}_{4}^{-}$, mainly to exclude the possibility of a falsely positive result due to the presence of an oesophageal diverticulus or a residual ingested fraction.

\section{HISTOLOGICAL EXAMINATIONS}

Baboons, 336, 342, and 482 were killed by exsanguination: lungs and thoracic lymph nodes were fixed in paraformaldehyde and embedded in paraffin wax. Five micrometre sections were cut and stained with either haematoxylin-eosin or Gordon-sweet for evaluation of fibrosis. The other animals are still under exploration for a long term study of their berylliosis. 
Comparative results of investigations performed on baboons with experimentally induced berylliosis

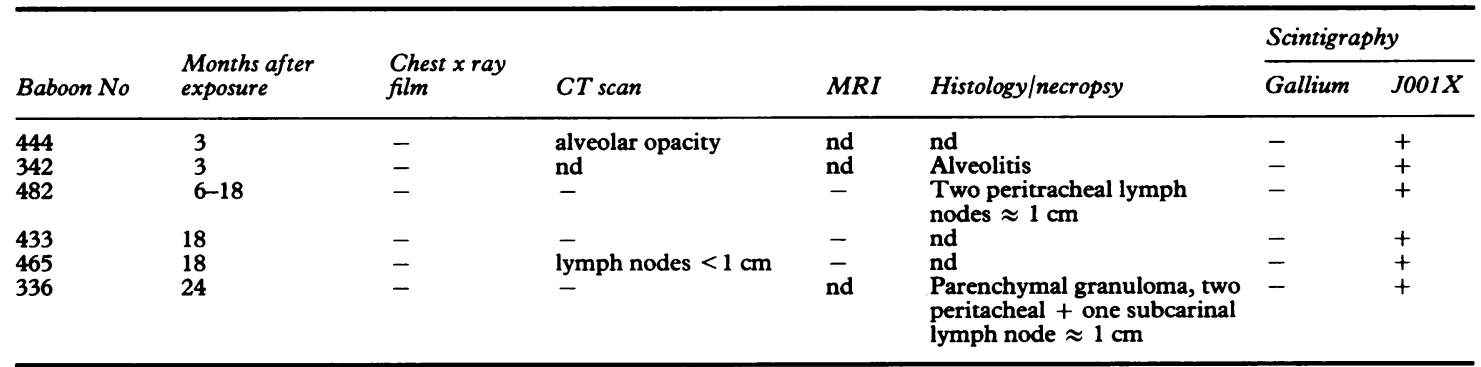

nd = Not done; - = not pathological; $+=$ fixation of J001X.

\section{Results}

In the six baboons, ${ }^{99 \mathrm{~m}} \mathrm{Tc}$ DTPA aerosol clearance was increased in the whole lungs. By contrast, none of the six animals exhibited any pathological feature on gallium scans. The results from J001X scintigraphy were analysed for each baboon, referring to other complementary investigations. The table presents the results of the investigations.

Baboon 444 was investigated three months after beryllium inhalation. No thoracic abnormality was evident on chest $x$ ray film. Computed tomography scan demonstrated an alveolar opacity in the right lower lobe. J001X scintigraphy disclosed a localised fixation which projected on the whole right lower lobe with an increasing concentration of the tracer from 70-140 mins after inhalation (fig 1). Using a ${ }^{99 m} \mathrm{Tc}$ oseophageal scintigraphy, the J001X fixation was differentiated from an oesophageal tract contamination occurring during the inhalation. No necropsy was performed at that time to allow the study of the evolution of the pathology.

Baboon 342 was investigated three months after beryllium contamination. At that stage, no thoracic abnormality was evident on chest $x$ ray film. From one to five hours after inhalation, J001X scintigraphy showed a localised fixation that projected on the right lower lobe. At necropsy, histological samples showed a severe alveolitis in the right lower lobe without parenchymal granuloma or mediastinal lymph nodes.

Baboon 482 was investigated monthly from six to 18 months after contamination. No thoracic abnormality was evident on chest $x$ ray film, computed tomography scan, and magnetic resonance imaging. J001X scintigraphy disclosed a focal fixation on the right side of the trachea (fig 2). A residual digestive activity was excluded using ${ }^{99 \mathrm{~m}}$ technetium oesophageal scintigraphy. At the necropsy, two enlarged lymph nodes, $10 \times 4 \mathrm{~mm}$ in size, were found on the right side of the trachea and under the carina, without any specific parenchymal feature.

Baboon 433 was investigated 18 months after beryllium contamination. No parenchymal abnormality was shown on chest $x$ ray film and computed tomography scan. No pathological feature appeared on magnetic resonance imaging. J001X scintigraphy showed a paratracheal fixation on the left side. It appeared one hour after inhalation and then extended to the paratracheal upper surrounding area until the fifth hour of observation. A combined analysis of oesophageal scintigraphy and angiocardiography led us to localise the fixation all along the trachea, behind the heart.

Baboon 465 was investigated 18 months after beryllium inhalation. Chest $x$ ray film was normal, and computed tomography scan showed mediastinal lymph nodes less than one $\mathrm{cm}$ in diameter. Magnetic resonance imaging gave normal findings. J001X

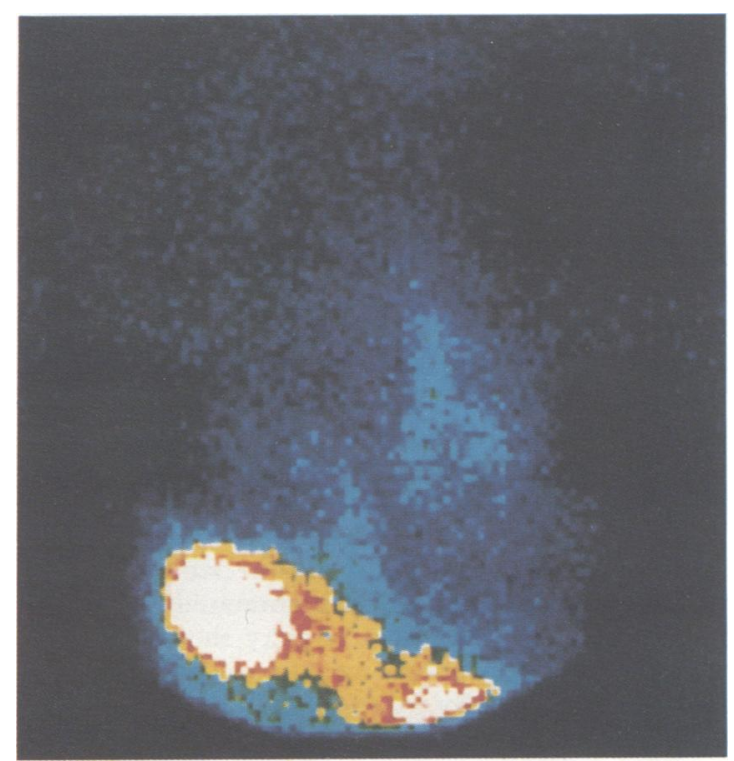

Figure 1 J001X scintigraphy in baboon No 342, three months after beryllium contamination: localised fixation in the right lung lower lobe located in an area histologically identified as an alveolitis (thorax posterior face, three hours after $J 001 X$ inhalation). 


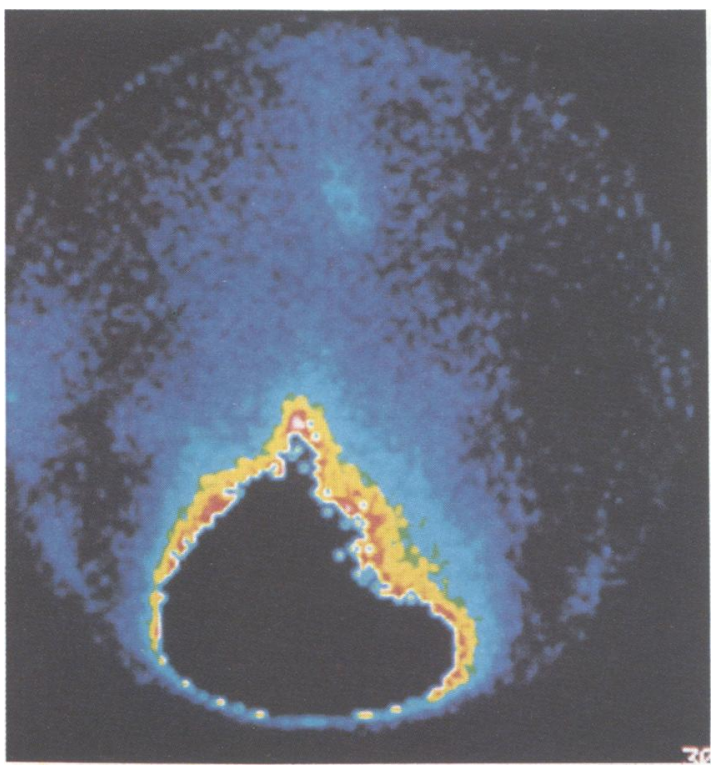

Figure 2 J001X scintigraphy in baboon No 482, 18 months after beryllium contamination: focal fixation on the right side of the trachea by an inflammatory lymph node $1 \mathrm{~cm}$ in diameter (thorax posterior face, three hours after J001X inhalation).

scintigraphy showed localised right laterotracheal fixation. This focus appeared five hours after J001X inhalation and persisted until the end of the examination (seven hours after administration). Based on ${ }^{99 \mathrm{~m}}$ technetium oesophageal scintigraphy, this J001X fixation was not related to a digestive contamination.

Baboon 336 was investigated 24 months after beryllium contamination. No thoracic abnormality was evident on chest $x$ ray film and computed tomography scan. J001X scintigraphy disclosed a focal fixation located on the right of the trachea. At necropsy, two peritracheal and one subcarinal enlarged lymph nodes were found, about one $\mathrm{cm}$ in diameter, associated with histologically confirmed parenchymal granuloma in the right lower lobe.

In summary, recently contaminated baboons (444, 342) showed a J001X fixation localised to the contaminated lobe and this fixation corresponded to an alveolitis histologically confirmed in baboon 342 . In the four other baboons, contaminated 12 to 24 months before, J001X scintigraphy showed mediastinal fixations corresponding to lymph nodes one $\mathrm{cm}$ or less in diameter. By contrast, gallium scintigraphy was always negative for all the animals.

\section{Discussion}

The early diagnosis of chronic berylliosis remains as yet a clinical problem in industrial medicine. In this study, J001X scintigraphy appeared to be efficient for the detection of occult experimental berylliosis via the targeting of macrophages that are involved in the granulomatous process.

In 1930, deaths occurred among workers in the fluorescent lamp industry after beryllium poisoning. ${ }^{17}$ The Atomic Energy Commission (AEC) set air standards for beryllium in $1949 .{ }^{8}$ For workplace air, an eight hour time weighted average maximum permissible level of $2.0 \mu \mathrm{g} / \mathrm{m}^{3}$ was established. These hygienic standards remain unchanged today and are adequate to prevent many cases of beryllium disease. Nevertheless, long term exposure with a low eight hour time weighted average air concentration or a brief very high exposure could have subclinical effects. So, chronic berylliosis continues to be an important professional lung disease.

Chronic beryllium disease primarily affects the lungs. ${ }^{29}$ The symptoms appear from a few months to 25 years after the beginning of exposure. The beryllium case registry at the Massachusetts General Hospital has defined criteria for chronic beryllium disease. ${ }^{9}$ Four of the following six features including one of the two first items are necessary: (1) epidemiological evidence of significant exposure to beryllium; (2) presence of beryllium in lung tissue, lymph nodes, or urine; (3) evidence of a lower respiratory tract disease and a clinical course consistent with beryllium disease; (4) radiological evidence of interstitial disease consistent with a fibronodular process; (5) evidence of a restrictive or obstructive ventilatory defect, or a diminished carbon monoxide diffusing capacity; (6) pathological changes consistent with beryllium disease on examination of lung tissue, or lymph nodes, or both.

In vitro tests were developed for an early diagnosis and a screening of longitudinal epidemiological studies among workers. ${ }^{40-13}$ Among these, lymphocyte transformation tests are still currently used but little is known about the significance of a positive result. ${ }^{12}{ }^{13}$ Does it mean a higher risk of disease if the exposure is continuing, or does it act only as a witness of the past exposure? It seems that beryllium exposure, moreover, could have subclinical and reversible effects when followed by a reduction of the exposure. ${ }^{9}$ So, diagnostic tests are needed to detect early symptoms of respiratory illness.

Alveolar macrophages are the first cells implicated in the immune response triggered by exposure to beryllium: ${ }^{14-16}$ they take up particulate beryllium compounds by phagocytosis and release lysosomal enzymes. ${ }^{17}$ In vitro experiments suggest that alveolar macrophages may present particulate beryllium to lymphocytes as a hapten binding to some large carrier molecules. In chronic beryllium disease, beryllium is the specific agent that stimulates local proliferation and accumulation in the lung of beryllium specific $\mathrm{CD} 4+$ (helper/inducer) $\mathrm{T}$ cells. ${ }^{18}$ Via lymphocyte 
secretion, sensitised $\mathrm{T}$ lymphocytes could regulate macrophage recruitment, monocyte maturation, and giant cell and epithelial cell formation, leading to granuloma development. ${ }^{10} 15$

Macrophages, newly recruited by inflammatory or tumour lesions, are able to interact in vitro with some bacterial proteoglycans. This property was recently applied to develop a new scintigraphic strategy using J001X labelled with ${ }^{99 \mathrm{~m}}$ technetium for imaging sarcoidosis and granulomatous diseases characterised by a macrophage infiltration. ${ }^{6} \mathrm{~J} 001 \mathrm{X}$ is a fully characterised and amphiphatic glycolipid isolated from Klebsiella membranes. Due to its low molecular weight (34 kD) and its amphiphatic structure, J001X is able to pass through the respiratory tract after aerosol administration. Under this condition, J001X rapidly diffuses into the blood, lymph, and extracellular space with a limited hepatosplenic uptake. In tissues, clearance of unbound J001X molecules occurs within three to five hours after administration. $^{6}$

In the present study, J001X scintigraphy has proved to be a good indicator of occult experimental berylliosis in baboons. In the six baboons who were studied, conventional imaging techniques such as chest $x$ ray film, computed tomography scan, magnetic resonance imaging and gallium scintigraphy, failed to reveal lung abnormalities or mediastinal lymph nodes consistent with beryllium disease. Indeed, good parenchymal slices were difficult to obtain on computed tomography scan due to the difficulties of obtaining a strict apnoea in baboons. This animal model, however, allowed us to investigate the two steps of chronic berylliosis. Two baboons $(342,444)$ were explored at the early stage of alveolitis after contamination and four baboons (336, $433,465,482$ ) were explored at a more advanced stage characterised by a granulomatous disorder such as inflamatory lymph nodes and parenchymal granulomas.

The same type of image was obtained with J001X in the two recently contaminated baboons: it appeared as a well defined parenchymal fixation that projected to the right lower lobe, the most contaminated part of the lung. Clearance of DTPA, a reference test for the assessment of alveolocapillary permeability ${ }^{19}$ was significantly increased in the whole lung. So, the abnormalities of alveolocapillary permeability induced by beryllium reach the whole lung. By contrast, the anatomical alterations at this early stage of alveolitis appeared in the most contaminated right lower lobe.

In the four baboons who were at a more advanced stage, J001X fixation was always focused on the sides of the trachea without any significant involvement of the parenchyma. Mediastinal lymph nodes that were detected on computed tomography scan were less than one $\mathrm{cm}$ in diameter and so they could not be considered as a pathological feature.$^{20}$ The subcarinal and laterotracheal lymph nodes found at necropsy in two baboons closely corresponded to the localisation disclosed by J001X scintigraphy. On the basis of the scintigraphic similarities, it may be reasonable to argue that the fixations seen in the two nonnecropsied baboons also corresponded to mediastinal lymph nodes. Thus J001X scintigraphy could be of value to assess the inflamatory process in thoracic lymph nodes.

In conclusion our data show that J001X scintigraphy could be a sensitive indicator to detect occult lung berylliosis both at the stages of early alveolitis and mediastinal berylliotic lymph nodes. This experimental study in baboons has proved its effectiveness when compared with conventional techniques. Further studies including workers exposed to beryllium are necessary to confirm the clinical value of this technique for the follow up of such patients.

Requests for reprints to: Patrice Diot, Laboratoire de Biophysique Cellulaire, Faculté de Médecine, 37032 Tours Cedex, France.

1 Cotes JE, Steel J. Beryllium disease. In: Cotes JE, Steel J, eds. Work-related lung disorders. Oxford: Blackwell Scientific Publications, 1987:232-41.

2 Kriebel D, Brain JD, Sprince NL, Kazemi HS. The pulmonary toxicity of beryllium. Am Rev Respir Dis 1988;137:464-73.

3 Sprince NL, Kazemi H. Beryllium Disease. In: Rom W, ed. Environmental and occupational medicine. 1st ed. Boston: Little Brown, 1983:481-90.

4 Hanifin JM, Epstein WL, Cline MJ. In vitro studies of granulomatous hypersensitivity to beryllium. I Invest Dermatol 1970;55:284-8.

5 Le Pape A. The targeting of macrophages with bacterial proteoglycans: a new strategy for the scintigraphic imaging of tumours and inflammatory lesions. Eur J Nucl Med 1989; 15:401.

6 Diot P, Le Pape A, Jubault C, Normier G, Pinel AM, Dussourd d'Hinterland L, et al. Potential use of bacterial proteoglycans for the in vivo targeting of macrophages: application to the scintigraphic imaging of sarcoidosis. Am Rev Respir Dis 1989;139:A190.

7 Hardy H. Beryllium disease: a clinical perspective. Environ Res 1980;21:1-9.

8 Eisenbud $M$. Origins of the standards for control of beryllium disease (1947-1949). Environ Res 1982;27:79-88.

9 Sprince NL, Kanarek DJ, Weber AL, Chamberlin RI, Kazemi H. Reversible respiratory disease in beryllium workers. $\mathrm{Am}$ Rev Respir Dis 1978;117:1011-7.

10 Deodhar SD, Barna B, Van Ordstrand HS. A study of the immunologic aspects of chronic berylliosis. Chest 1973;63: 309-13.

11 Price CD, Pugh A, Pioli EM, Jones Williams W. Beryllium macrophage migration inhibition test. Ann NY Acad Sci 1976;278:204-11.

12 Williams WR, Jones Williams $W$. Comparison of lymphocyte transformation and macrophage inhibition tests in the detection of beryllium hypersensitivity. J Clin Pathol 1982;35: 684-7.

13 Jones $W$ illiams $W$, Williams WR. Value of beryllium lymphocyte transformation tests in chronic beryllium disease and in potentially exposed workers. Thorax 1983;38:41-4.

14 Daniele RP, Elias JA, Epstein PE, Rossman MD. Bronchoalveolar lavage: role in the pathogenesis, diagnosis and management of interstitial lung disease. Ann Intern Med 1985; 102:93-108.

15 Daniele RP. Cell-mediated immunity in pulmonary disease. Hum Pathol 1986;17:154-60. 
16 Epstein PE, Dauber JH, Rossman MD, Daniele RP. Bronchoalveolar lavage in a patient with chronic berylliosis: evidence for hypersensitivity pneumonitis. Ann Intern Med 1982; 97:213-6.

17 Kang KY, Bice D, D'Amato R, Ziskind M, Salvaggio J. Effects of asbestos and berylium on release of alveolar macrophage enzymes. Arch Environ Health 1979;34:133-40.

18 Saltini C, Winestck K, Kirby M, Pinkston P, Crystal RG. Maintenance of alveolitis in patients with chronic beryllium disease by beryllium-specific helper T cells. $N$ Engl J Med 1989;320:1103-9.
19 Rinderknecht J, Shapiro L, Krauthammer M, Taplin G, Wasserman $K$, Uszler M, Effros RM. Accelerated clearance of small solutes from the lungs in interstitial lung disease. $\mathrm{Am}$ Rev Respir Dis 1980;121:105-17.

20 Libshitz HI, McKenna RJ, Hayni TP, McMurtrey MJ, Mountain CE. Medistinal evaluation in lung cancer. Radiology 1984;151:295-9.

Accepted 8 July 1991

\section{Destruction of manuscripts}

From 1 July 1985 articles submitted for publication will not be returned. Authors whose papers are rejected will be advised of the decision and the manuscripts will be kept under security for three months to deal with any inquiries and then destroyed. 